Volume 113, Number 1

heart rate response can be similar to that of the transplanted heart, ${ }^{2}$ the attenuated heart rate response to exercise early after the maze procedure may be caused by denervation of the sinoatrial node as a result of multiple incisions in the atrial wall. If the attenuated heart rate response to exercise early after the maze procedure was caused by denervation of the sinoatrial node, recovery of the heart rate response late after operation can be explained by the time course of reinnervation of the sinoatrial node. ${ }^{3}$

ANPs have been extracted from atrial myocytes of mammals, including human beings, and play an important role in natriuresis and vasodilation. Because ANP was excreted markedly after exercise, the determination of plasma ANP level after exercise allows evaluation of the atrial function as the excretion ability. Percent increase of ANP after exercise was higher in the late phase than that in the control and early phases, which suggests that atrial function of ANP excretion was restored over time.

Transient atrial dysfunction occurred in patients with atrial fibrillation who underwent electrical cardioversion, and mechanical atrial function is reduced when conversion is achieved after atrial fibrillation has been sustained for more than a week. ${ }^{4}$ The mechanism of atrial dysfunction after elimination of atrial fibrillation is unknown. Shapiro and colleagues ${ }^{4}$ postulated that postischemic stunned atrial myocardium, as in the occurrence of ischemia during ventricular fibrillation, may explain this phenomenon.
The delayed recovery of atrial function may influence the improved exercise capacity in the late phase after combined treatment consisting of surgical repair for organic heart disease and atrial fibrillation.

We conclude that transient attenuation of atrial function, seen as sinoatrial node response, excretion of ANP, and mechanical contractility, occurred in patients after combined treatment with surgical repair for heart disease and the maze procedure for atrial fibrillation. The late recovery of atrial function may improve exercise capacity over time.

\section{REFERENCES}

1. Cox JL, Schuessler RB, D'Agostino HJ, et al. The surgical treatment of atrial fibrillation: III-development of a definitive surgical procedure. J Thorac Cardiovasc Surg 1991;101: $569-83$.

2. Ehrman J, Keteyian S, Fedel F, Rhodas K, Levine TB, Shepard R. Cardiovascular responses of heart transplant recipients to graded exercise testing. J Appl Physiol 1992;73: $153-66$.

3. Peiss CN, Cooper T, William VL, Randall WC. Circulatory responses to electrical and reflex activation of the nervous system after cardiac denervation. Circ Res 1966;19:153-66.

4. Shapiro EP, Effron MB, Lima S, Ouyang P, Siu CO, Bush D. Transient atrial dysfunction after conversion of chronic atrial fibrillation to sinus thythm. Am J Cardiol 1989;13:617-23.

\title{
CEREBRAL EMBOLIZATION IS REDUCED WITH USE OF THE STAB TECHNIQUE FOR AORTIC CANNULATION COMPARED WITH THE SIDE-CLAMP TECHNIQUE
}

\author{
Uday Trivedi, FRCS, Christopher Davies, BSc, James Roxburgh, MS, FRCS(C/Th), and \\ Graham Cooper, MD, FRCSEd(C/Th), London, United Kingdom
}

Manipulation of the heart and ascending aorta during cardiac operations is an important cause of cerebral emboli. ${ }^{1,2}$ To date there has been no reported study on the influence of aortic cannulation technique and the prevalence of cerebral microemboli. We compared the production of emboli, measured in the left middle cerebral artery with transcranial Doppler imaging between the side-clamp technique of aortic cannulation and the stab technique. Both techniques involve trauma to the aortic wall and the possibility of releasing atheromatous debris

From the Department of Cardiothoracic Surgery, St. Thomas' Hospital, London, United Kingdom.

Received for publication Jan. 10, 1996; accepted for publication June 20, 1996.

Address for reprints: U. H. Trivedi, FRCS, Department of Cardiothoracic Surgery, St. Thomas' Hospital, Lambeth Palace Road, London, SE1-7EH, England.

J Thorac Cardiovasc Surg 1997;113:215-6

Copyright (C) 1997 by Mosby-Year Book, Inc.

$0022-5223 / 97 \$ 5.00+0 \quad \mathbf{1 2 / 5 4 / 7 6 0 4 7}$ and of allowing air to enter during the introduction of the cannula. Transcranial Doppler ultrasonography is unable to differentiate gaseous from particulate emboli accurately, but it is a useful method to measure the total number of emboli that reach the brain. Because the middle cerebral artery supplies $80 \%$ of the ipsilateral cerebral hemisphere, measurement of emboli within this vessel will reffect the total embolic load for each hemisphere.

Patients and methods. Twenty patients undergoing elective cardiac operations were prospectively randomized to either the stab (group S) or side-clamp (group C) technique of aortic cannulation. Cannulation was done by one of two senior surgeons (J. R. and G. C.) in equal numbers with each technique, and both surgeons were equally conversant with both techniques. All patients were undergoing first-time elective operation, and those with cerebrovascular disease were excluded.

The two cannulation techniques are similar, but in the stab technique a transverse incision is made in the aorta with a scalpel and as the scalpel is withdrawn the aortic cannula is introduced through the incision. In the sideclamp technique, a Cooley side-biting clamp is used to 


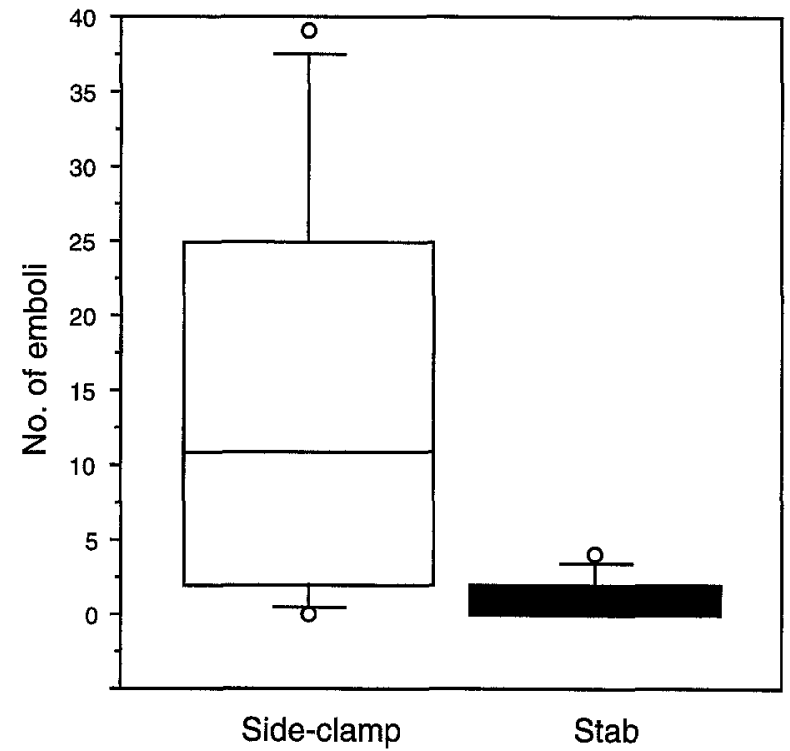

Fig. 1. Box plot shows incidence of cerebral emboli with two cannulation techniques.

exclude a portion of the aortic wall, which is then incised vertically, and as the side clamp is released the aortic cannula is inserted. A Sarns $24 \mathrm{~F}$ gauge cannula (3M Health Care, Ann Arbor, Mich.) was used for all cases. The left middle cerebral artery was chosen because it provides the appropriate embolus-to-blood ratio to maximize embolus detection and has been used in a number of previous studies that examined emboli during cardiopulmonary bypass. ${ }^{3}$ Emboli were identified by their short duration, characteristic "chirp," and amplitudes greater than or equal to $10 \mathrm{~dB}$ from the background Doppler signal. ${ }^{4}$ The audio signal was recorded for 2 minutes before cannulation and for 2 minutes after cannulation. Emboli were subsequently counted by an independent, experienced observer blinded to the cannulation technique (U. T.).

Results are expressed as median with interquartile (IQR) and absolute (AR) ranges. Emboli counts were compared with a Mann-Whitney U test. Comparison of proportions was made by $\chi^{2}$ test. A probability of less than $5 \%(p<0.05)$ was considered significant.

Results. There were no major differences in patient characteristics (Table I). All patients, except one, were undergoing elective coronary artery bypass operation. All cannulations were uncomplicated. There were significantly fewer emboli with the stab technique (median 1, IQR 0 to 2 , AR 0 to 4 ) compared with the number with the side-clamp technique (median 11 , IQR 2 to 25, AR 0 to 39) ( $p=0.01$ ) (Fig. 1). The one patient who underwent aortic valve replacement was in group $C$ and had one embolic event associated with cannulation.

Discussion. Microemboli occur at various stages of cardiac operations, principally at cannulation, commencement of cardiopulmonary bypass, and, maximally, on
Table I. Patient characteristics for the two cannulation groups

\begin{tabular}{lccc}
\hline & Group $S$ & Group C & p Value \\
\hline Age (yr) & $60.5 \pm 11.3$ & $58.9 \pm 7.9$ & $0.65^{*}$ \\
Sex (M:F) & $10: 0$ & $7: 3$ & $0.06 \dagger$ \\
BSA $\left(\mathrm{m}^{2}\right)$ & $1.9 \pm 0.2$ & $2.0 \pm 0.1$ & $0.37^{*}$ \\
\hline
\end{tabular}

Data shown as mean \pm standard deviation where appropriate. $M$, Male; $F$, female; $B S A$, body surface area,

*Mann-Whitney U test.

$\uparrow \chi^{2}$ analysis.

filling and subsequent beating of the heart. In coronary artery bypass operations cannulation is the third most embolic procedure after removal of partial aortic occlusion clamps and cardiac manipulation, and patients with embolic counts greater than 60 have a significantly higher risk of morbidity and mortality. ${ }^{2}$

The validity of Doppler ultrasonography in emboli detection during cardiopulmonary bypass is established. ${ }^{1}$ In our study we limited the period of observation to that covering aortic cannulation. All aortas were deemed to be normal by palpation, which, although not as accurate as intraoperative ultrasonography, would be sufficient to detect any gross pathologic condition.

If one takes the threshold embolic load to be 60 emboli, ${ }^{2}$ then in group $\mathrm{C}$ aortic cannulation accounted for $18.3 \%$ of the level versus $3.3 \%$ in group $\mathrm{S}$. With both cannulation techniques it is possible to have both gaseous and particulate emboli. We believe that both types of emboli are involved during cannulation. In group $C$ we did observe embolic signals with the application of the aortic side clamp. It may be that with the side-clamp technique a greater proportion of the emboli are of a particulate nature than with the stab technique. We conclude that the stab technique is associated with significantly fewer cerebral microemboli, with a possible reduction in morbidity. It should be used in preference to the side-clamp technique.

We thank Drs. O'Riordan, Shabbo, Venn, and Young for permission to include their patients in this study.

\section{REFERENCES}

1. Stump DA, Tegeler CH, Rogers AT, et al. Neuropsychological deficits are associated with the number of emboli detected during cardiac surgery (abstract). Stroke 1993;24:509.

2. Clarke RE, Brillman J, Davis DA, Lovell MR, Price TRP, Magovern GJ. Microemboli during coronary artery bypass grafting: genesis and effect on outcome. J Thorac Cardiovasc Surg 1995;109:249-57.

3. Moehring MA, Klepper JR. Pulse Doppler ultrasound detection, characterization and size estimation of emboli in flowing blood. IEEE Trans Biomed Eng 1994;41:35-44.

4. Spencer MP, Thomas GI, Nicholls SC, Sauvage LR. Detection of middle cerebral artery emboli during carotid endarterectomy using transcranial Doppler ultrasonography. Stroke 1990;21:415-23. 